\title{
THE SURFACE PROPERTIES OF BARIUM TITANATE*
}

\author{
P. BUCHMAN† \\ Electrical Engineering Department, University of Michigan, Ann Arbor Michigan, U.S.A.
}

(Received 14 December 1967; in revised form 4 March 1968)

\begin{abstract}
Semiconductor thin films are used to study the ferroelectric surface. The observed $n$-type germanium, deposited on $\mathrm{BaTiO}_{3}$ at elevated temperatures, is explained on the basis of the ferroelectric space-charge layer. The piezoresistance effect in semiconductors provides a tool for the study of surface strains in $\mathrm{BaTiO}_{3}$, particularly at crystallographic phase transitions.
\end{abstract}

Résumé-Des pellicules fines semiconductrices sont employées pour étudier la surface ferroélectrique. Le germanium de type $n$ observé, déposé sur le $\mathrm{TiO}_{3} \mathrm{Ba}$ à des températures élevées est expliqué sur la base de la couche de charge d'espace ferro-électrique. L'effet de piézorésistance du semiconducteur fournit un moyen d'étudier les tensions des surfaces dans le $\mathrm{TiO}_{3} \mathrm{Ba}$, particulièrement durant les transitions cristallographiques de phase.

Zusammenfassung--Halbleiter-Dünnschichten werden zur Untersuchung der ferroelektrischen Oberflächen herangezogen. Wird eine Germaniumschicht bei erhöhter Temperatur auf $\mathrm{BaTiO}_{3}$ niedergeschlagen, so zeigt diese n-Charakter, was auf Grund der ferroelektrischen Raumladungsschicht zu erklären ist. Der Piezo-Widerstands-Effekt von Halbleitern ermöglicht die Untersuchung von Oberflächenspannungen an $\mathrm{BaTiO}_{3}$, besonders bei Phasenübergängen.

\section{INTRODUCTION}

THE FIELD effect interaction between a semiconductor film and a ferroelectric surface may be thought of as a diagnostic technique to study either the ferroelectric or the semiconductor. Our main interest here is in the use of the semiconductor to study the ferroelectric surface. Two types of experiments will be described. The first deals with the effect of surface space-charge layers of $\mathrm{BaTiO}_{3}$ on films of germanium and tellurium. The second type concerns the use of the piezoresistance of semiconductor films to study surface strains in $\mathrm{BaTiO}_{3}$, particularly at crystallographic phase transitions.

A large number of experimental results ${ }^{(1-16)}$ on $\mathrm{BaTiO}_{3}$ crystal indicate that there exists a surface layer with properties different from the bulk. On the basis of X-ray and electron diffraction $\mathrm{KANZIG}^{(1)}$ suggested the existence of an ionic or electronic space-charge layer on the surface

* Supported by the Electrovoice Corporation, Buchanan, Michigan.

† Present address: Battelle Northwest, Richland, Washington. of $\mathrm{BaTiO}_{3}$. Further evidence for the existence of a space-charge has been given by CHYNOWETH ${ }^{(2)}$ and Triebwasser. ${ }^{(8)}$ The model proposed by Triebwasser is that of a so-called Schottky exhaustion barrier with a donor concentration of $10^{19} / \mathrm{cm}^{3}$. JANOVEC ${ }^{(11)}$ proposed that antiparallel domains exist on the surface of the ferroelectric. The anti-parallel domains result in a positive space-charge layer on both surfaces of the $\mathrm{BaTiO}_{3}$.

\section{EXPERIMENTAL RESULTS AND DISCUSSION}

(1) The effect of $\mathrm{BaTiO}_{3}$ space-charge layer on the properties of deposited germanium films

In this section we describe the formation of an n-type evaporated layer obtained for thin Ge films deposited on $\mathrm{BaTiO}_{3}$ at elevated temperatures. This result is explained on the basis of the spacecharge layer on the surface of $\mathrm{BaTiO}_{3}$.

Germanium films were vacuum deposited at $10^{-6}$ torr on etched $\mathrm{BaTiO}_{3}$ crystals. The semiconductor films with thicknesses ranging from 400 to $1500 \AA$ were deposited at substrate temperatures of $650^{\circ}-750^{\circ} \mathrm{C}$. Germanium films were also deposited on quartz and mica for comparison. 
Table 1. Electrical data for germanium films on $\mathrm{BaTiO}_{3}$ crystals

\begin{tabular}{|c|c|c|c|c|c|c|}
\hline & Mica & $\mathrm{BaTiO}_{3}$ & $\mathrm{BaTiO}_{3}$ & $\mathrm{BaTiO}_{3}$ & $\mathrm{BaTiO}_{3}{ }^{*}$ & $\mathrm{BaTiO}_{3}{ }^{*}$ \\
\hline Substrate temperature, ${ }^{\circ} \mathrm{C}$ & 600 & 650 & 700 & 700 & 750 & 750 \\
\hline Thickness $\AA$ & 600 & 1200 & 500 & 400 & 400 & 400 \\
\hline Resistivity, $\Omega-\mathrm{cm}$ & 2 & $2 \times 10^{-2}$ & $5.8 \times 10^{-2}$ & $10 \times 10^{-2}$ & $1.12 \times 10^{-2}$ & $9.7 \times 10^{-3}$ \\
\hline Carrier density $/ \mathrm{cm}^{3}$ & $7.8 \times 10^{17}$ & $3.8 \times 10^{18}$ & $2 \times 10^{19}$ & $4 \times 10^{19}$ & $6 \times 10^{20}$ & $3 \times 10^{20}$ \\
\hline Hall mobility, $\mathrm{cm}^{2} \mathrm{~V}^{-1} \mathrm{sec}^{-1}$ & 4 & 82 & 5 & 1.5 & 1 & 2 \\
\hline $\begin{array}{l}\text { Field effect mobility at } 30 \mathrm{H}_{2} \\
\mathrm{~cm}^{2} \mathrm{~V}^{-1} \mathrm{sec}^{-1}\end{array}$ & 0.4 & 一 & 一 & - & 一 & - \\
\hline Type & $p$ & $p$ & $n$ & $n$ & $n$ & $n$ \\
\hline
\end{tabular}

* Hall measurements for both surfaces of a $\mathrm{BaTiO}_{3}$ crystal.

The results of the deposition and subsequent Hall effect measurements are summarized in Table 1. These data are unusual in several respects. In the first place, it is noted that thin films of Ge $(500 \AA)$ are strongly $n$-type on $\mathrm{BaTiO}_{3}$ whereas a thicker film $(1200 \AA)$ is $p$-type. To our knowledge, this is the only reported instance of an $\boldsymbol{n}$-type evaporated Ge film on any substrate. Ge has always deposited as $p$-type unless it was purposely doped. Ge ( $400 \AA$ thick) was deposited on both sides of one $\mathrm{BaTiO}_{3}$ crystal. Hall effect measurements showed both films to be strongly $n$-type. There are two possible explanations, $(a)$ a diffusion of impurities from the $\mathrm{BaTiO}_{3}$ may 'dope' the semiconductor; (b) the space-charge layer at the $\mathrm{BaTiO}_{3}$ surface may cause, via the field effect, an $n$-type channel in a normally $p$-type film. Considering the former possibility, it is difficult to see which impurity in $\mathrm{BaTiO}_{3}$ could invert the film. Ferric oxide added to the crystal to enhance growth is probably the largest impurity. However, iron in germanium forms a deep acceptor level. This, coupled with the fact that the $n$-type carrier density appears to be large, leads us to believe that the $\mathrm{BaTiO}_{3}$ surface controls the film by a field mechanism.

To develop a tentative model, consider the conditions at the $\mathrm{BaTiO}_{3}$ surface during the deposition of Ge. The crystal is held at $700^{\circ} \mathrm{C}$ for $1 \mathrm{hr}$ in vacuum. It is known ${ }^{(17,18)}$ that under these circumstances, loss of oxygen will take place. The reduced $\mathrm{BaTiO}_{3}$ surface then effectively has a very high density of positively ionized donors due to oxygen vacancies. The Ge atoms at the surface do not tend to fill the oxygen vacancies because $\mathrm{Ge}$ is not sufficiently electronegative to bind with orbitals in the Ba or Ti sites. This high density of positive ionized donors induces negative carriers on the adjacent Ge surface. The suggested energy band diagram for this interface is shown in Fig. 1.

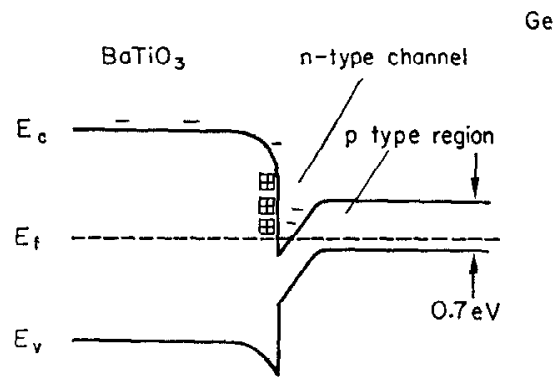

FIG. 1. Suggested energy band diagram for $\mathrm{BaTiO}_{3}-\mathrm{Ge}$ interface.

It is seen that an $n$-type channel is induced in the $p$-type Ge film. If the film is very thin, the $n$ channel dominates. For thick films, the $p$ region dominates which explains why we observe the $p$-type films for thicknesses in excess of $1200 \AA$. For the $p$-type $\mathrm{Te}$ on $\mathrm{BaTiO}_{3}$, recall that $\mathrm{Te}$ deposition has to be done at lower substrate temperatures. Hence, the $\mathrm{BaTiO}_{3}$ surface would not be as highly reduced. Furthermore, $\mathrm{Te}$ is strongly electronegative and has an electron configuration similar to oxygen. Thus, Te can actually occupy the oxygen vacancies and may compensate for the donor states in the $\mathrm{BaTiO}_{3}$ surface. Under these conditions, the $n$-type channel is not formed. Also, with this configuration, Te should be more susceptible to the field effect than germanium. 
This model is consistent with the scheme proposed by JaNovec ${ }^{(11)}$ and others wherein the $\mathrm{BaTiO}_{3}$ surface consists of a positive space-charge layer and thus the electric field from this layer is directed inward from the surface. Negative surface charge layers, at least for our conditions, would not appear to fit this picture.

\section{(2) Piezoresistance of semiconductor films on} $\mathrm{BaTiO}_{3}$

A BaTiO ${ }_{3}$ crystal undergoes phase transitions at about $120^{\circ}, 5^{\circ}$ and $-90^{\circ} \mathrm{C}$. At these temperatures the crystal lattice undergoes a discontinuous change in dimension. Semiconductor films such as $\mathrm{Ge}$ and $\mathrm{Te}$ deposited on a $\mathrm{BaTiO}_{3}$ crystal will exhibit a piezoresistance effect at the phase transitions. From such data one can study the changes in the lattice dimension of the $\mathrm{BaTiO}_{3}$ surface once the properties of the film are independently known. For a Te film the piezoresistance and field effect are mixed making the interpretation of the data difficult. The field effect for a Ge film, once exposed to air is degraded to a large extent. Therefore, the change in the resistance of the film at the phase transition is due mainly to a piezoresistance effect.

The temperature dependence of the resistance of Ge film deposited on $\mathrm{BaTiO}_{3}$ is shown in Fig. 2. The figure includes typical results for both $p$ - and $n$-types of film. The $n$-type film was obtained by deposition on a $\mathrm{BaTiO}_{3}$ crystal held at $700^{\circ} \mathrm{C}$ as described in a previous section.

In order to interpret the above data, consider first a $p$-type Ge film (I, cf. Fig. 2), the resistance of which increases with tension. Starting with a polarized crystal at $25^{\circ} \mathrm{C}$ the unit cell presents to the surface an ' $a$ ' dimension. At the Curie temperature, the resistance of the film increases as a result of a discontinuous increase in the surface area of the $\mathrm{BaTiO}_{3}$. Upon cooling, the surface contains a mixture of ' $a$ ' and ' $c$ ' dimensions and the surface area decreases gradually with decrease in temperature. Upon polarizing the crystal, the resistance again decreases due to a decrease in surface area. This cycle is independent of the direction in which the crystal is polarized indicating that the effect observed is due only to a piezoresistance effect. By cooling the $c$-oriented

Table 2. Electrical data for tellurium and germanium films

\begin{tabular}{|c|c|c|c|c|c|c|c|c|}
\hline Substrate & Film & $\begin{array}{c}\text { Thickness } \\
\AA\end{array}$ & $\begin{array}{c}\text { Substrate } \\
\text { temperaturc, } \\
{ }^{\circ} \mathrm{C}\end{array}$ & $\begin{array}{c}\rho^{*} \\
\Omega-\mathrm{cm}\end{array}$ & $\begin{array}{c}p^{*} \\
\text { holes } / \mathrm{cm}^{3}\end{array}$ & $\begin{array}{c}\mu_{H}^{*} \\
\mathrm{~cm}^{2} \mathrm{~V}^{-1} \\
\sec ^{-1}\end{array}$ & $\begin{array}{c}\mu_{r e}{ }^{*} \\
\mathrm{~cm}^{2} \mathrm{~V}^{-1} \\
\sec ^{-1}\end{array}$ & $\begin{array}{l}\text { Measured } \\
P_{s} \times 10^{-6}, \\
\mathrm{C} / \mathrm{cm}^{2}\end{array}$ \\
\hline Mica & $\mathrm{Te}$ & 1000 & 25 & 4 & $10^{ \pm 7}$ & 17 & 4 & - \\
\hline Mica & Te & 760 & 25 & 2.5 & - & - & 1.45 & - \\
\hline Mica & $\mathrm{Te}$ & 1400 & 25 & 3 & $1.2 \times 10^{17}$ & 16 & - & - \\
\hline Mica & $\mathrm{Te}$ & 900 & 140 & $7.7 \times 10^{-2}$ & - & - & - & - \\
\hline $\mathrm{BaTiO}_{3}$ & Te & 400 & 25 & $2.6 \times 10^{-1}$ & $\begin{array}{c}10^{18} \\
\text { estimated }\end{array}$ & - & $\begin{array}{l}6.5 \\
5 \cdot 7\end{array}$ & $14 \cdot 8$ \\
\hline $\mathrm{BaTiO}_{3}$ & $\mathrm{Te}$ & 1400 & 25 & $\begin{array}{l}1.23 \\
3.82\end{array}$ & $\begin{array}{l}1.4 \times 10^{17} \\
6.7 \times 10^{16}\end{array}$ & $\begin{array}{l}34 \\
24\end{array}$ & $\begin{array}{l}8 \\
2\end{array}$ & 18.2 \\
\hline $\mathrm{BaTiO}_{3}$ & $\mathrm{Te}$ & 760 & 25 & $\longrightarrow$ & $\longrightarrow$ & - & $\begin{array}{l}1.9 \\
1.3\end{array}$ & - \\
\hline $\mathrm{Ba}^{\prime} \mathrm{TiO}_{3}$ & ' I'e & 750 & 25 & $1.48 \times 10^{-1}$ & $\begin{array}{l}2.2 \times 10^{18} \\
\text { estimated }\end{array}$ & - & $\begin{array}{l}4 \cdot 7 \\
3.85\end{array}$ & 9.1 \\
\hline $\mathrm{BaTiO}_{3}$ & $\mathrm{Te}$ & 300 & 140 & $4 \times 10^{-2}$ & $7.8 \times 10^{18}$ & $\cdots$ & $\begin{array}{c}12 \\
\text { noisy }\end{array}$ & - \\
\hline Mica & $\mathrm{Ge}$ & 600 & 600 & 2 & $7.8 \times 10^{17}$ & 4 & 0.4 & - \\
\hline Quartz & $\mathrm{Ge}$ & 3000 & 650 & $2.6 \times 10^{-2}$ & $1.3 \times 10^{18}$ & 170 & - & - \\
\hline $\mathrm{BaTiO}_{3}$ & $\mathrm{Gc}$ & 1200 & 650 & $2 \times 10^{-2}$ & $3.8 \times 10^{1 \mathrm{~B}}$ & 82 & - & $\cdots$ \\
\hline $\mathrm{BaTiO}_{3}$ & $\mathrm{Ge}$ & 300 & 600 & $2.7 \times 10^{-1}$ & - & - & 0.75 & 17.5 \\
\hline $\mathrm{BaTiO}_{3}$ & $\mathrm{Ge}$ & 400 & 25 & 90 & - & - & $\ll 1$ & - \\
\hline $\mathrm{BaTiO}_{3}$ & Ge & 640 & 2.5 & 100 & - & - & $10^{-4}$ & 22.1 \\
\hline
\end{tabular}

* These values are voltage dependent for $\mathrm{Te}$ on $\mathrm{BaTiO}_{3}$. 


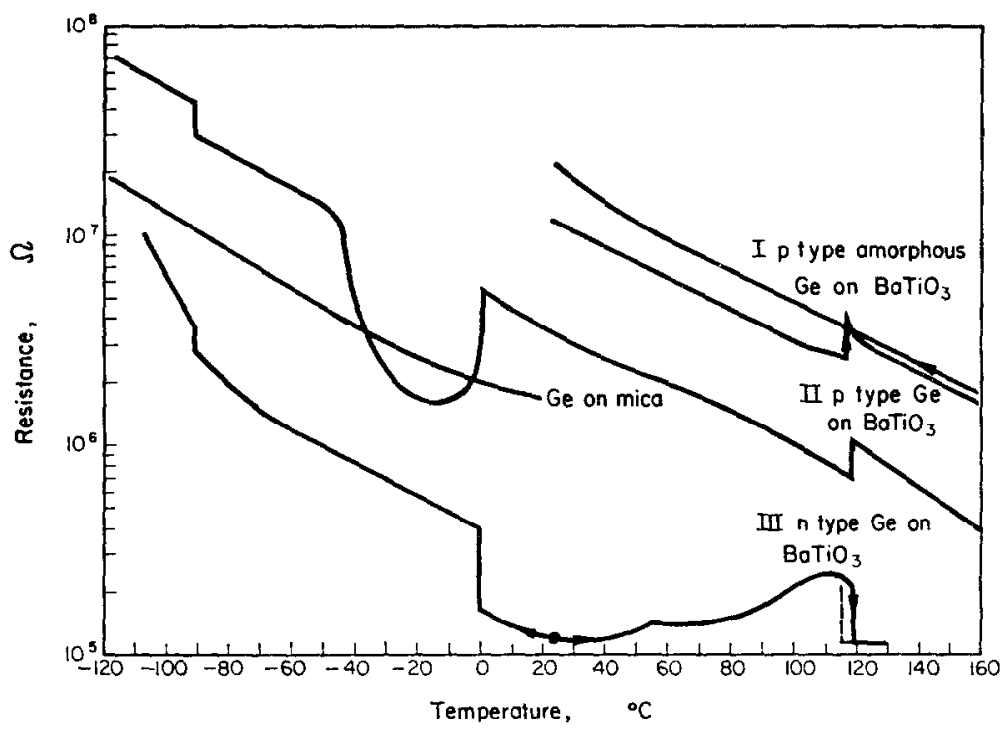

FIG. 2. Piezoresistance effect in germanium films on $\mathrm{BaTiO}_{3}$ at phase transitions.

crystal from $25^{\circ} \mathrm{C}$ the resistance of the $p$-type $\mathrm{Ge}$ film abruptly decreases at $0^{\circ}$, and increases at $-90^{\circ} \mathrm{C}$. A similar result is observed for an $n$-type film (III, cf. Fig. 2), the resistance of which decreases with tension, except at the transition from orthorhombic to rhombohedral. At this phase transition the result for the $n$-type Ge does not agree with that of the $p$-type film.
The changes in the resistance of Ge film at phase transitions of $\mathrm{BaTiO}_{3}$ and an estimation of the strain at the cubic to tetragonal phase transition are given in Table 3 . It is shown that the surface area of a $c$-oriented crystal expands discontinuously by approximately 1.2 per cent as the crystal is heated through the Curie temperature. The calculation for the strain is based on the gage

Table 3. Piezoresistance effect in germanium films at $\mathrm{BaTiO}_{3}$ phase transitions

\begin{tabular}{|c|c|c|c|c|c|c|}
\hline \multirow[b]{2}{*}{ Sample } & \multirow[b]{2}{*}{ Type } & \multicolumn{4}{|c|}{ Calculated } & \multirow[b]{2}{*}{ Remarks } \\
\hline & & $\begin{array}{l}\frac{\Delta R}{R} \% \\
c \rightarrow T\end{array}$ & $\begin{array}{l}\frac{\Delta A}{A} \% \\
c \rightarrow T\end{array}$ & $\begin{array}{c}\frac{\Delta R}{R} \% \\
T \rightarrow O\end{array}$ & $\begin{array}{l}\frac{\Delta R}{R} \% \\
O \rightarrow R\end{array}$ & \\
\hline I & $p$ & -32 & -1.28 & - & - & $\begin{array}{l}\text { The field was removed after polarizing at } 20^{\circ} \mathrm{C} \text {. } \\
\text { Measured for both directions of polariza- } \\
\text { tion. }\end{array}$ \\
\hline II & $p$ & -30 & -1.15 & -68 & +43.5 & $\begin{array}{l}\text { Before cooling, the field was removed after } \\
\text { polarizing at } 20^{\circ} \mathrm{C} \text {. Measured for both direc- } \\
\text { tions of polarization. }\end{array}$ \\
\hline III & $n$ & +20 & -0.8 & +150 & +34 & Same as II. \\
\hline IV & $n$ & +41 & -1.64 & - & - & \\
\hline
\end{tabular}

$C=$ cubic, $T=$ tetragonal, $O=$ orthorhombic, $R=$ rhombohedral. Unless otherwise stated, the crystals were heated and cooled through the Curie temperature under an applied field slightly larger than the coercive field ( 5 to $10 \mathrm{~V})$. 


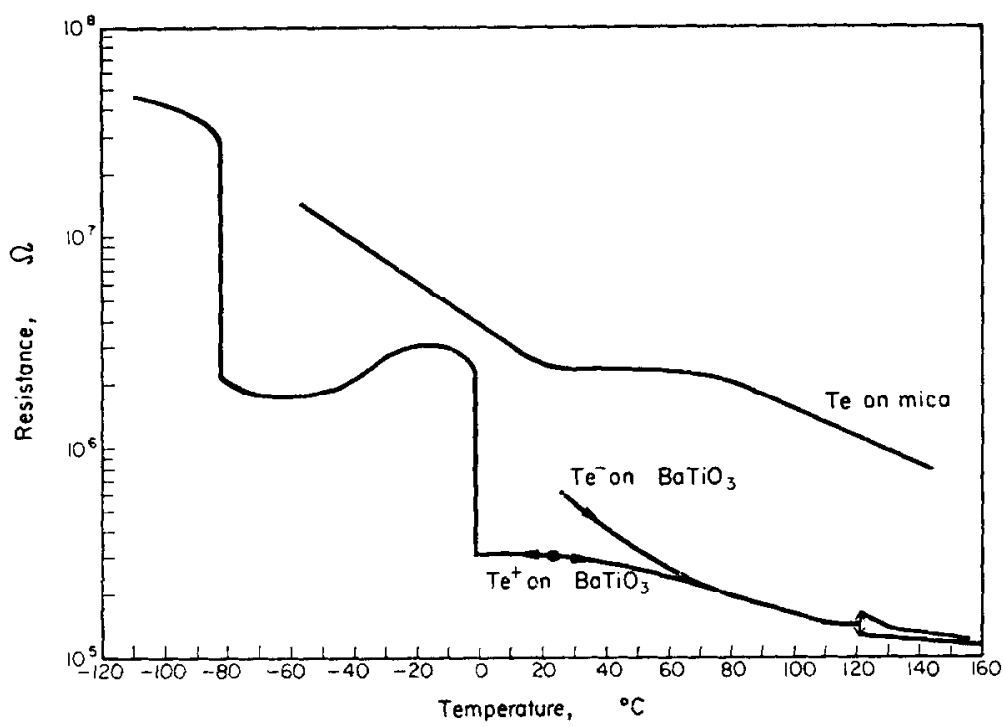

Fig. 3. Piezoresistance effect in tellurium films on $\mathrm{BaTiO}_{3}$ at phase transitions.

factor obtained for Ge film deposited on glass and mica substrate and the assumption that the strain in the width of the film, deposited on $\mathrm{BaTiO}_{3}$, is equal to the strain in its length. This assumption is well justified for the tetragonal to cubic phase transition. Estimation of the change in the lattice constant of $0^{\circ}$ and $-90^{\circ} \mathrm{C}$ from the piezoresistance measurement is difficult since in addition to changes in surface area the crystal no longer appears flat. Large regions of the surface form root like triangular ridges and depressions which may contribute to the piezoresistance effect. Our result for the change in area of the crystal surface at the tetragonal-cubic phase transition agrees in direction with that of KAY and Vousden. ${ }^{(19)}$ The magnitude, however, is about 4 times larger. It must be pointed out that KAY and VousDEN ${ }^{(19)}$ used an $\mathrm{X}$-ray diffraction technique which is not particularly surface sensitive whereas our method is strictly a surface effect.

\section{CONCLUSIONS}

It was shown that a semiconductor film can be used to study several aspects of ferroelectric crystals. In particular, it appears that a high density of positive space-charge may exist at both surfaces of a $\mathrm{BaTiO}_{3}$ crystal. It is possible to use the piezoresistance of semiconductors, in conjunction with other measurements, to study stress at ferroelectric surfaces. This effect is sensitive enough, for the case of Ge films, to enable one to measure a strain of the order of $1 \times 10^{-4}$. The surface of a $c$-oriented crystal expands discontinuously by 1.2 per cent as the crystal is heated through the Curie temperature.

Acknozledgment-The writer expresses his thanks and appreciation to Professor Howard Diamond of the University of Michigan for suggesting the problem and for stimulating discussions.

\section{REFERENCES}

1. W. Kanzig, Phys. Rev. 98, 549 (1955).

2. A. G. Chynoweth, Phys. Rev. 102, 705 (1956).

3. W. J. Menz, J. appl. Phys. 27, 938 (1956).

4. M. E. Drougrad and R. Landauer, J. appl. Phy's. 30, 1663 (1959).

5. E. FAtuzzo and W. J. Mrkz, J. appl. Phys. 32, 1685 (1961).

6. R. C. Miller and A. Savage, J. appl. Phys. 30, 808 (1959).

7. R. C. Miller and A. Savage, J. appl. Phys. 31, 662 (1960).

8. S. Triebwasser, Phys. Rev. 118, 100 (1960).

9. G. G. Harman, Phys. Rev. 111, 27 (1958). 
10. M. ScholjET, Phys. Status Solidi 4, 639 (1964).

11. V. Janovec, Czech. J. Phys. 9, 468 (1959).

12. V. Dvorak, Czech. J. Phys. 9, 710 (1959).

13. B. Brezina and A. A. Fotcenkov, Czech. J. Phys. B-14, 21 (1964).

14. B. Brezina and V. Janovec, Czech. J. Phys. B-14 45 (1964).

15. R. Williams, J. Physics Chem. Solids 26, 399 (1965).
16. D. R. Callaby, J. appl. Phys. 36, 2751 (1965); $J$. appl. Phys. 37, 2295 (1966).

17. S. IKegami and I. Ueda, J. phys. Soc. Japan 19, 159 (1964).

18. I. UEDA and S. IkEgAMI, J. phys. Soc. Japan 20, 546 (1965).

19. H. F. KAY and P. Vousden, Phil. Mag. 40, 1019 (1949). 